\title{
Dossiê: Ecologia humana e saúde
}

\section{Apresentação}

\section{Márcia Grisotti* Ana Paula Saccol**}

Em setembro de 2010 o Núcleo de Ecologia Humana e Saúde,
com o apoio do Programa de Pós-Graduação em Sociologia Política e a Fundação de Apoio à Pesquisa Científica e Tecnológica de Santa Catarina, realizou o 1ํㅗำ Seminário de Sociologia da Saúde e Ecologia Humana - 1ํㅡㄹ.

O objetivo do seminário foi articular e fortalecer debates interdisciplinares sobre a compreensão dos processos e experiências de saúde-doença e da tomada de decisões institucionais em saúde; promover essa linha de pesquisa no âmbito das disciplinas relacionadas às ciências sociais, saúde e ecologia humana e articular pesquisadores e profissionais dessas áreas com vistas à criação de uma rede de cooperação com as instituições públicas ligadas a essa temática. Com mais de 100 trabalhos inscritos em Grupos de Trabalho, as apresentações contemplaram reflexões teóricas e empíricas sobre diversos temas, relacionados aos debates atuais sobre as estratégias científicas de resolução de problemas nas diversas esferas da saúde e das questões ambientais globais e complexas da atualidade, nas quais os fatos são incertos, os valores estão em disputa, os riscos são altos e as decisões urgentes (FUNTOWICZ; RAVETZ, 1997). Os grupos de trabalho foram divididos em 06 eixos temáticos: Interdisciplinaridade nas

Professora do Departamento de Sociologia e Ciência Política e Coordenadora do Núcleo de Ecologia Humana e Saúde, Florianópolis, Universidade Federal de Santa Catarina. Endereço eletrônico: grisotti@fastlane.com.br

*** Doutoranda pelo Programa de Pós Graduação em Sociologia Política. Integrante do Núcleo de Ecologia Humana e Saúde, Florianópolis, Universidade Federal de Santa Catarina. Endereço eletrônico: anasaccol@ccs.ufsc.br. 
Ciências Sociais, Ecologia Humana e Saúde; Doenças emergentes; Políticas públicas em saúde; Representações sociais em saúde; e Saúde e Alimentação. Dentre os temas do Encontro selecionamos para figurarem neste Dossiê os trabalhos relativos à ecologia humana e às políticas de saúde.

$\mathrm{O}$ artigo de Emilio Moran, Transformation of Social and Ecological Systems, analisa o longo processo de transformação dos sistemas sociais e ecológicos, ocorrido principalmente pelo crescimento populacional, apropriação dos recursos naturais e aumento da complexidade dos sistemas, bem como, identifica algumas das mudanças necessárias para resolver (ou tentar resolver) os problemas decorrentes desse processo como no caso de emissões de gases que provocam o aquecimento global, das mudanças climáticas e da perda de diversidade biológica e cultural.

$\mathrm{O}$ artigo de Maria Cecília de Souza Minayo, Da inteligência parcial ao pensamento complexo: desafios da ciência e da sociedade contemporânea, apresenta uma discussão sobre as noções teóricas e metodológicas que hoje fazem parte do vocabulário do mundo das ciências e das práticas profissionais como: multidisciplinaridade, multiprofissionalidade, interdisciplinaridade, transdisciplinaridade e pensamento complexo. De uma forma didática, realça alguns autores e conceitos das teorias complexas, considerados como mais aptos para enfrentarem situações de incerteza, ruídos e crises ao contrário das ciências tradicionais que lidam com regularidades, previsibilidade e verdades estabelecidas.

O artigo de Fernando Dias de Avila Pires, Human ecology, statistical analysis, and the logic of valid correlations, discute os limites das correlações estatísticas utilizadas nas pesquisas epidemiológicas quando elas carecem de reflexividade e precisão, enfatizando os seus impactos na interpretação da realidade. Para isso, analisa alguns fatores comumente utilizados nas pesquisas: sexo, idade, estado civil, ocupação, religião e raça.

Jorge Márquez e Oscar Gallo, no artigo Hacia una historia de la lucha antituberculosa en Colômbia, analisam a história social e cultural do controle da tuberculose na Colômbia, no final do século XIX e 
início do século XX. Com base em uma extensa análise de dados históricos e discursos, os autores desenvolvem a argumentação do artigo através da pergunta: tratava-se de um problema sanitário coletivo, em termos biomédicos e epidemiológicos, ou conformava apenas um conjunto de representações sociais e culturais baseadas nos estigmas atribuídos a essa enfermidade?

Carmem Rosario Ortiz Gutierrez Gelinski em seu artigo A questão da co-responsabilidade prevista na Estratégia Saúde da Familia, analisa o novo modelo assistencial em saúde proposto em 1997 e executado através da Estratégia Saúde da Família (ESF). Focaliza o sentido do termo co-responsabilidade outorgado, pelo novo modelo, às famílias e às equipes de saúde. O artigo aponta que enquanto os operadores em saúde, notadamente as equipes de ESF, têm uma lista de atribuições que delimitam a sua atuação, as famílias não sabem como executar a sua parte da coresponsabilidade.

O artigo de Kênia Gaedtke e Márcia Grisotti, Os Conselhos Municipais de Saúde: uma revisão da literatura sobre seus limites e potencialidades, faz uma revisão da literatura sobre os dilemas da consolidação dos conselhos municipais de saúde no Brasil. Grande parte da produção acadêmica apresenta o fato de que a institucionalização dos conselhos de saúde não garante necessariamente o efetivo controle social, participação e democratização das políticas de saúde. Procura-se mostrar que as dificuldades encontradas pelos conselhos para sua efetividade e legitimidade resultam de diversos fatores interdependentes, que, se analisados isoladamente, podem levar a conclusões simplistas. 